TAO, Vol. 15, No. 4, 565-587, November 2004

\title{
Morphology and Dynamic Sedimentology in front of the Retreating Tsengwen Delta, Southwestern Taiwan
}

\author{
Eason Hong ${ }^{1, *}$, Tien-Chi Huang ${ }^{1}$ and Ho-Shing Y ${ }^{2}$ \\ (Manuscript received 9 February 2004, in final form 17 June 2004)
}

\begin{abstract}
The Tsengwen Delta exhibits subsidence, erosion and retreat of shorelines. The once river-dominated irregularly protruded delta has evolved into a wave-dominated cuspate one with smooth gently curving shorelines. Subprofiler/sidescan sonar data, precision depth echo-sounding and 150 grab samples are integrated to reveal the bathymetry, bedforms, sediment distribution and their governing processes in front of the retreating Tsengwen Delta.

Different bathymetry, bedforms, and sediment distribution patterns are found north and south of the offshore of the delta. These discrepancies reflect different interactions of the river influx, topography, and hydrodynamics, resulting in different stages of delta abandonment and subsidence. The spatial sediment distributions not only indicate the future evolution of this destructive delta but also help us to recognize and constrain the interpretation of ancient delta sequences.
\end{abstract}

(Key words: LOICZ, Tsengwen Delta, 3.5 kHz Echogram, Retreating delta, Sediment distribution, Bathymetry)

\section{INTRODUCTION}

The Tsengwen River is the third largest river in Taiwan draining into the southern Taiwan Strait (Fig.1). The drainage basin, with an area of $1177 \mathrm{~km}^{2}$, includes part of the southwestern rugged foothills and fertile coastal plain (Chang 2000). In the past, the Tsengwen River continuously carried abundant sediments and deposited on its floodplain. The annual mean sediment load was estimated to be 31 million metric tons and a mean water discharge of

\footnotetext{
${ }^{1}$ Institute of Applied Geosciences, National Taiwan Ocean University, Keelung, Taiwan, ROC

2 Institute of Oceanography, National Taiwan University, Taipei, Taiwan, ROC

* Corresponding author address: Prof. Eason Hong, Institute of Applied Geosciences, National Taiwan Ocean University, Keelung, Taiwan, ROC; E-mail: eason@mail.ntou.edu.tw
} 
$2.36 \times 10^{9} \mathrm{~m}^{3}$ (Chen and Chang 2001). As deposition proceeded, the Tsengwen Delta built seaward with an aggradation rate estimated to be 70 meters per year from 1904 to 1990 (Chang 2000).

Within the last two hundred years, the Tsengwen River had switched its river course four times (Chang 2000; Chen and Chang 2001). Whenever an avulsion occurred, the abundant discharged sediment made the newly formed river channel extended outward into the sea. Before 1973, with the extrusion, bifurcation and long finger-like channels (Tseng et al. 1996), the Tsengwen Delta, evolved into a fluvial-dominated delta (following the classification schemes of Galloway 1975; Elliott 1986).

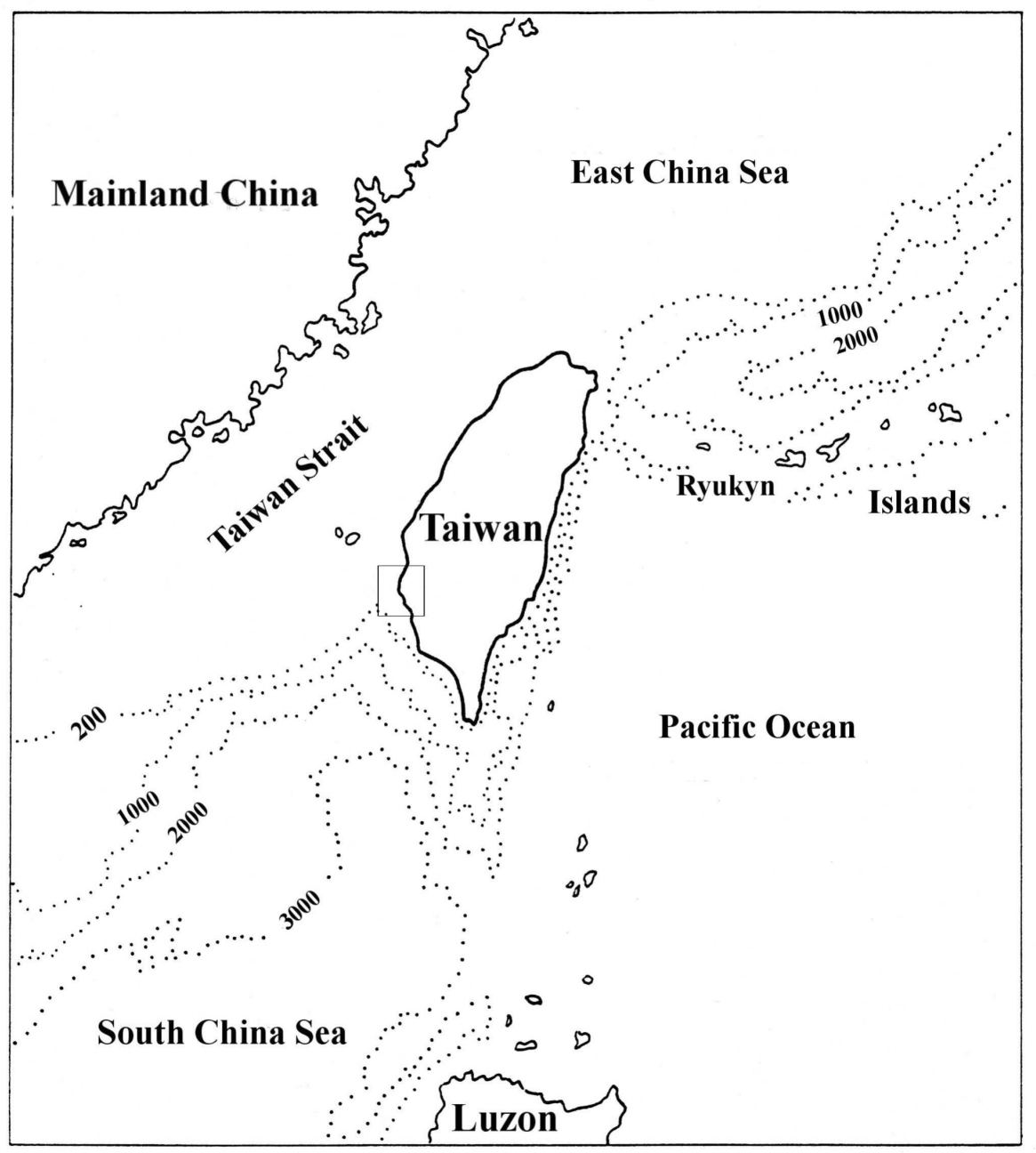

Fig. 1. Location of the study area. The unit of the bathymetric contour is in meters. 
However, after the Tsengwen Dam construction in 1973, an average of 12.4 million metric tons of sediment has been deposited in the reservoir behind the dam each year over a tenyear period (Yeh et al. 1994). Which means that almost 40 percent of the annual discharge of sediments has now been cut off. Since then, with its shoreline adjusting continuously to a reduction in fluvial sediment and shoreline processes, the Tsengwen Delta has been gradually retreating (Shih et al. 1995) and evolving into a wave-dominated cuspate form. The present delta configuration is characterized by smooth straight barrier islands and their hinder lagoons to the north of the cusp, whilst to the south is the river mouth and a gently curving shoreline with well-developed beaches (Fig. 2).

These discrepancies in shoreline configuration are definitely the result of differing governing processes. Therefore, this study tries to integrate findings from a subprofiler and sidescan combined high-resolution sonar investigation, bathymetry data and 150 grab samples to reveal details about the morphology and general distribution of sediment types off the retreating Tsengwen Delta. From which, the interpretation of subaqueous morphology and sediment distribution patterns will then provide insights into the processes that control sediment transportation, deposition and their influence on the response of the shoreline. Accordingly, the character and future evolution of this destructive delta will be better understood and predicted.

\section{PHYSICAL SETTING}

Presently, the tip of the cuspate Tsengwen Delta is near the Tsengwen River mouth. The cusp of the delta acts as a demarcation separating those areas north and south of the cusp into two distinctive coastal regions (Fig. 2). North of the cusp, the linear shoreline is trending NNE-SSW and includes a chain of long and narrow barrier islands associated with their landward lagoons and wet lands. To the south, the coastline is curves gently and is characterized by beaches and estuaries.

The offshore region of the Tsengwen Delta is dominated by moderate to high energy waves and weak tidal currents. The tidal range is small and generally less than one meter. The wave field is closely influenced by seasonal monsoon wind patterns. From October to April, waves are driven by northeasterly winds. At this time, significant wave height in the northern offshore ranges from $2.56-2.58 \mathrm{~m}$. However, owing to shielding provided by the cuspate promontory, significant wave height in the southern part is subdued to between $0.8-0.11 \mathrm{~m}$ (Wen et al. 1995). This is not the case from June through August, however, when waves are affected by southwesterly winds and occasional summer storms (typhoons). During this period, wave energy is higher in the southern offshore area with significant wave height ranging from $0.12-4.32 \mathrm{~m}$; these results contrast with a smaller and narrower range of $1.0-1.25 \mathrm{~m}$ recorded in the north (Wen et al. 1995).

\section{METHOD}

The High frequency $(3.5-12 \mathrm{kHz})$ profiler and sidescan sonar have long been widely used separately to study sediment distribution and regional sedimentation processes (Damuth 


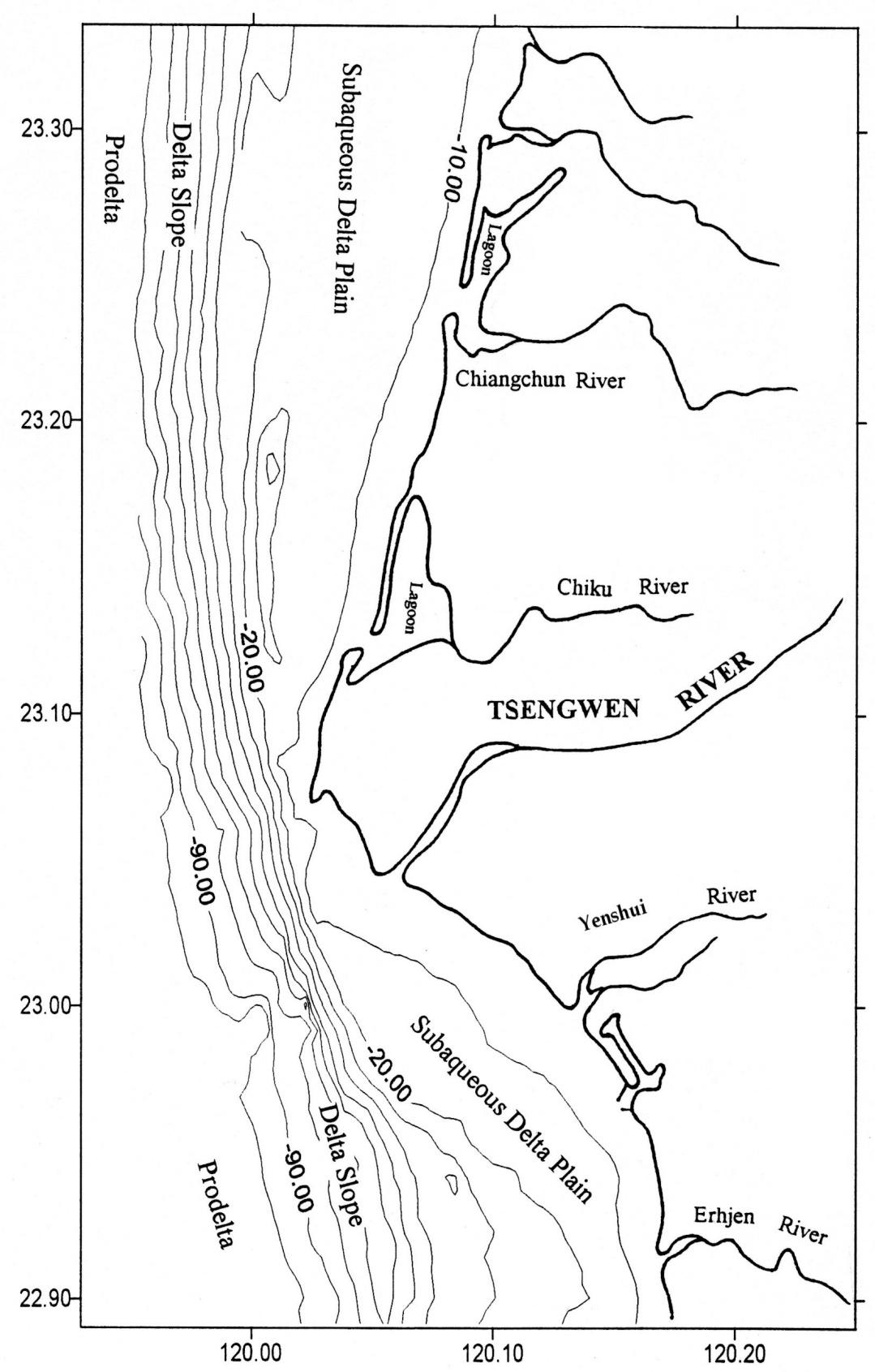

Fig. 2. Bathymetric chart showing the subaqueous delta plain, delta slope and prodelta in front of the Tsengwen Delta. Different configurations of the shorelines are also illustrated. 
1980; Hong et al. 2000). By lacking accompanying side-scan sonographs, however, interpretations of some echo characteristics in previous studies must inevitably be speculative. Therefore, a combined three-channel sidescan and profiler sonar system ought be much more helpful in understanding the relationship between various echo characters and reflectivity changes to the actual micro-topography and lithology.

Furthermore, in the previous times, almost all the single $3.5 \mathrm{kHz}$ profilers had been used to study deeper marine setting (Alexander et al. 1986; McClennen 1989; Harris et al. 1993; Knebel 1993; Schwab et al. 1996; Hong and Chen 2000). And yet only the prolonged echo type was able to be distinguished from the shelf setting. Fortunately, the Chirp profiler, sweeping a range of frequencies, was developed in the late 1980's and this machine has been able to produce better resolution of sediments lying on and below the seabed than previous singlefrequency profilers (LeBlanc et al. 1992; Morang et al. 1997). Hence, this study deploys a combined GeoAcoustic side-scan and GeoChirp profiler sonar system to study sediments of the uppermost sea floor and the surface bedforms. Accordingly, the regional sedimentation and transportation processes in this shallow subaqeuos deltaic environment will be revealed to delineate its future coastal evolution.

The surveys were made on RV Ocean Researcher II and III in both monsoon seasons from 1994 to 1999. During the operations at sea, continuous profiles and side-scan sonographs were obtained throughout the entire study area (Fig. 3). The total swath width per trackline of the GeoAcoustic $100 \mathrm{kHz}$ sidescan sonar system was $200 \mathrm{~m}$ with a ship speed approximately 4 knots. Along with this seismic operation, the bathymetry was also surveyed with a $38 \mathrm{kHz}$ Simrad echo sounder.

In addition, 150 sediment samples were collected from the seafloor surface (Fig. 4) with a grab sampler. During sampling, a Fisher's DV-2 underwater video system was occasionally deployed to observe or to check the surface sediments if significant loss of sediments during grab recovery was suspected. Navigation and positioning for these surveys were by the Tremble navigation system.

\section{RESULTS}

\subsection{Subaqueous Topography}

Collected depth data were processed with Surfer software to produce bathymetric contour map of the study area (Fig. 2). Based on the map, the subaqueous topography off the Tsengwen Delta is divided into three physiographic portions, the subaqueous delta plain, delta slope and prodelta. The subaqueous delta plains are flat (less than $0.1^{\circ}$ ) and mostly shallower than $20 \mathrm{~m}$. In front of the apex of the Tsengwen Delta, there is a bank on the subaqueous delta plain. This bank is roughly rectangular with dimensions $2 \times 0.8 \mathrm{~km}^{2}$. The bank is generally $10 \mathrm{~m}$ in depth and is $3 \mathrm{~m}$ above the nearby northern and southern subaqueous delta plain. Meanwhile, the southern margin of the bank is dissected by an east-west trending channel which is a paleochannel of the Tsengwen River. Accordingly, this bank and its southern channel form a natural divide separating northern and southern subaqueous delta plains. It is worth noting that there is a NNE-SSW trending ridge bordering the northern subaqueous delta plain margin. 


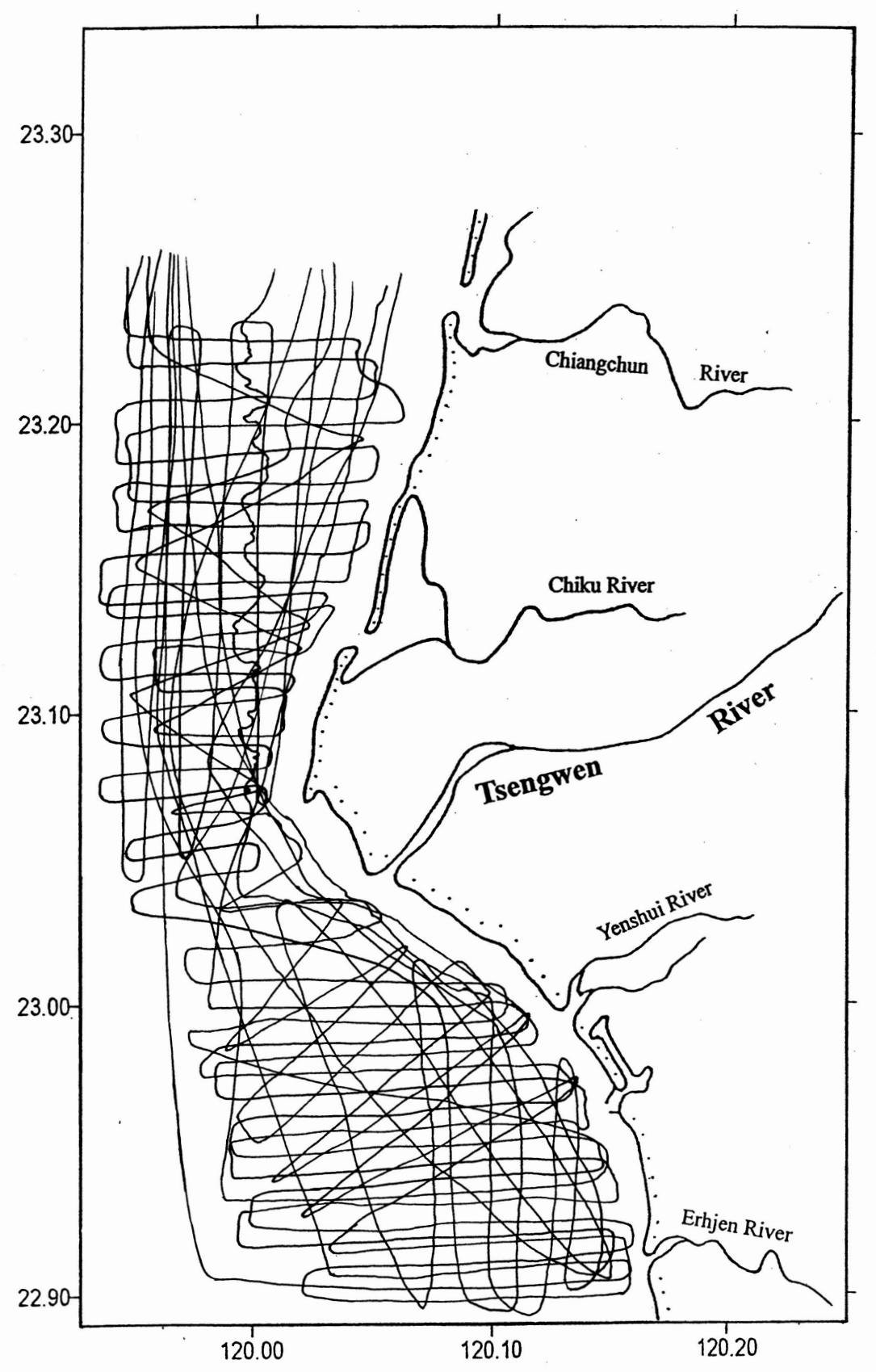

Fig. 3. Location of combined $3.5 \mathrm{kHz}$ profiler and sidescan sonar surveying tracks indicated by solid lines. 


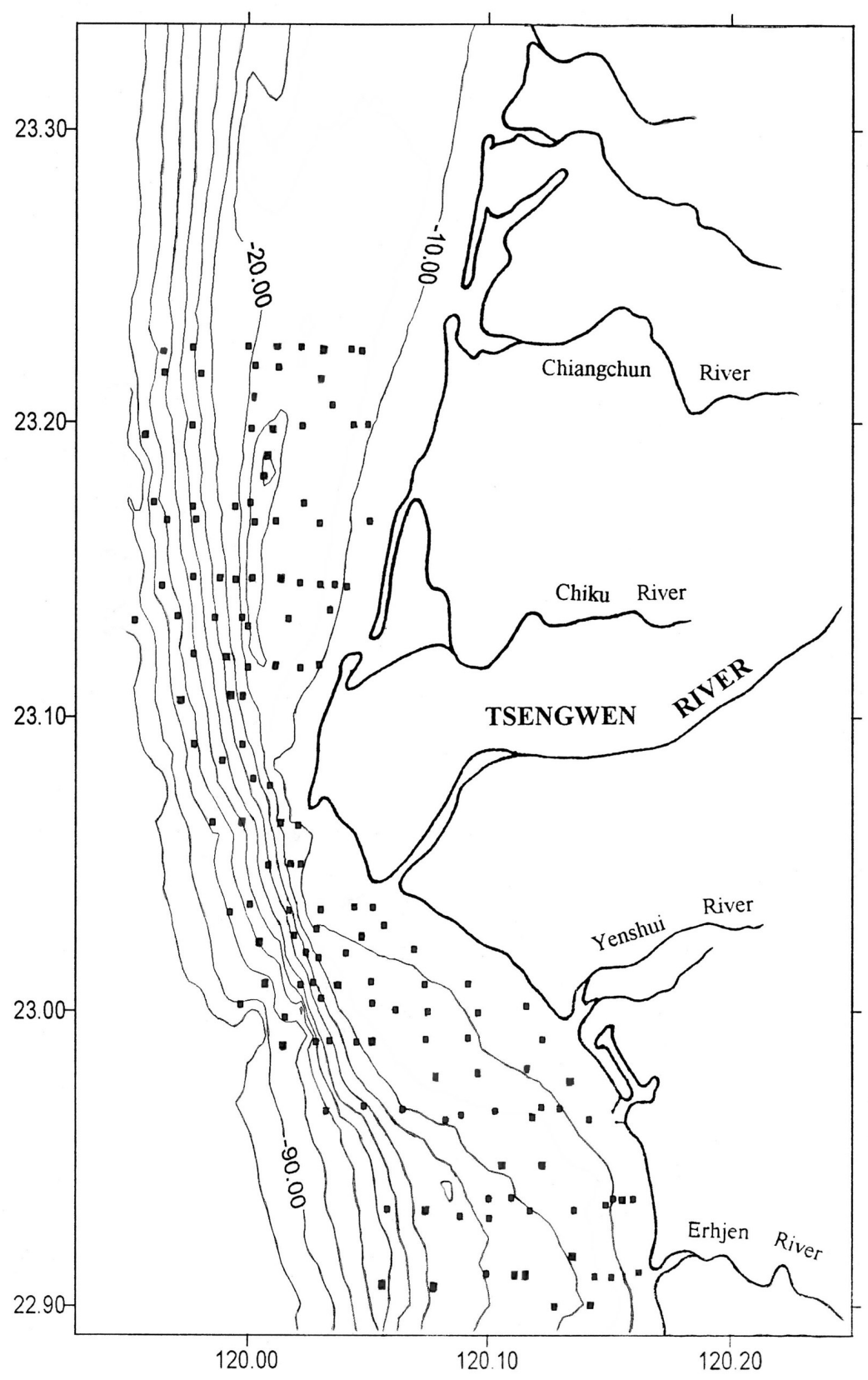

Fig. 4. Bathymetric chart showing locations (filled square) where the 150 grab samples were taken for grain size analysis. 
The maximum height of this ridge is $8 \mathrm{~m}$. There is no ridge along its southern counterpart.

All subaqueous delta plains are bordered by delta slope. This slope varies between 20 to $90 \mathrm{~m}$ in depth (Fig. 2). The average gradient of the northern delta slope is $0.67^{\circ}$, while the southern delta slope averages $1.36^{\circ}$. However, the steepest slope of the region occurs in front of the apex of the delta with a gradient of $1.47^{\circ}$. At the foot of the delta slope is the prodelta which is more than $90 \mathrm{~m}$ in depth. The gradient of the prodelta is gentler than those in delta slope. Based on limited data in the prodelta, the average gradient is estimated at $0.36^{\circ}$.

\subsection{Classification of Echo Types}

The high frequency $(3.5-12 \mathrm{kHz})$ profiler and sidescan sonar have long been widely used individually to study sediment distribution and regional sedimentation processes (Damuth 1980; Alexander et al. 1986; McClennen 1989; Hong et al. 1992; Harris et al. 1993; Knebel 1993; Schwab et al. 1996). However, a combined three-channel sidescan and profiler sonar system is much more helpful in understanding the relationship of various reflectivity changes to the actual microtopography and lithology. In addition, as mentioned previously, the GeoChirp profiler, sweeping a range of frequencies $(2-8$ or $1.5-11.5 \mathrm{kHz})$, was developed in the late 1980 's to get better resolution of sediments lying on and below the seabed than previous single $3.5 \mathrm{kHz}$ profilers.

In this study, echo types are classified on the basis of acoustic character and microtopography or morphology of the sea floor as proposed by Damuth (1980). The reflection intensity and microtopography or morphology revealed on the counterpart sidescan sonograph are also used to assist in recognizing, classifying and explaining echo types. Furthermore, the sedimentological interpretations of various echo types and sidescan sonograph in other studies (Damuth 1980; Addy et al. 1982; Alexander Jr. et al. 1986; Nittrouer et al. 1986; Pratson and Laine 1989; Knebel 1993; Moustier and Matsumoto 1993; Schwab et al. 1996) are referred to in this study to equate each echo type with a distinctive type of sedimentary deposit.

Accordingly, seven distinctive echo types characterizing the sediment distribution on the subaqueous delta plain, delta slope and prodelta are recognized in this shallow deltaic environment. These echo types were grouped into either distinct or indistinct classes as follows:

\section{A. Distinct echoes:}

Distinct echoes are characterized by a sharp, continuous, smooth bottom echo. This echo type is further divided into three subclasses.

I. Thick distinct echoes (the thickness of the surface echo is about $1.1 \mathrm{~m}$ ):

Ia. Distinct echoes without sub-bottom reflectors (Fig. 5); low acoustic backscatter area with light appearance on side-scan sonograph.

Ib. Distinct echoes with indistinct parallel, continuous sub-bottom reflectors (Fig. 5); The depth of penetration is about $10 \mathrm{~m}$; high acoustic backscatter area with gray appearance on side-scan sonograph. 
II. Thin distinct echoes (the thickness of the surface echo is about $0.6 \mathrm{~m}$ ):

IIa. Distinct echoes without sub-bottom reflectors (Fig. 6); high acoustic backscatter area with gray appearance on sidescan sonograph.

IIb. Distinct echoes with parallel, continuous sub-bottom reflectors (Fig. 6): The depth of penetration is about $20 \mathrm{~m}$; high acoustic backscatter area with gray appearance on side-scan sonograph.

IIc. Distinct echoes with vague discontinuous sub-bottom reflectors or simply semiprolonged (Fig. 6); low acoustic backscatter area with light appearance on sidescan sonograph.

III. Distinct to semi-prolonged bottom echoes with long wavelength wavy surface (Fig. 7). On the counterpart side-scan sonograph, there are very large 2-D dunes (wavelength ranged from $140-220 \mathrm{~m}, 2-6 \mathrm{~m}$ in wave height), with medium 2-D dunes (wavelength $5-10 \mathrm{~m}$, height $0.4-0.9 \mathrm{~m}$ ) superimposed on the trough areas. The nomenclature of the subaqueous bedforms mainly follows the classification scheme of Ashley (1990).

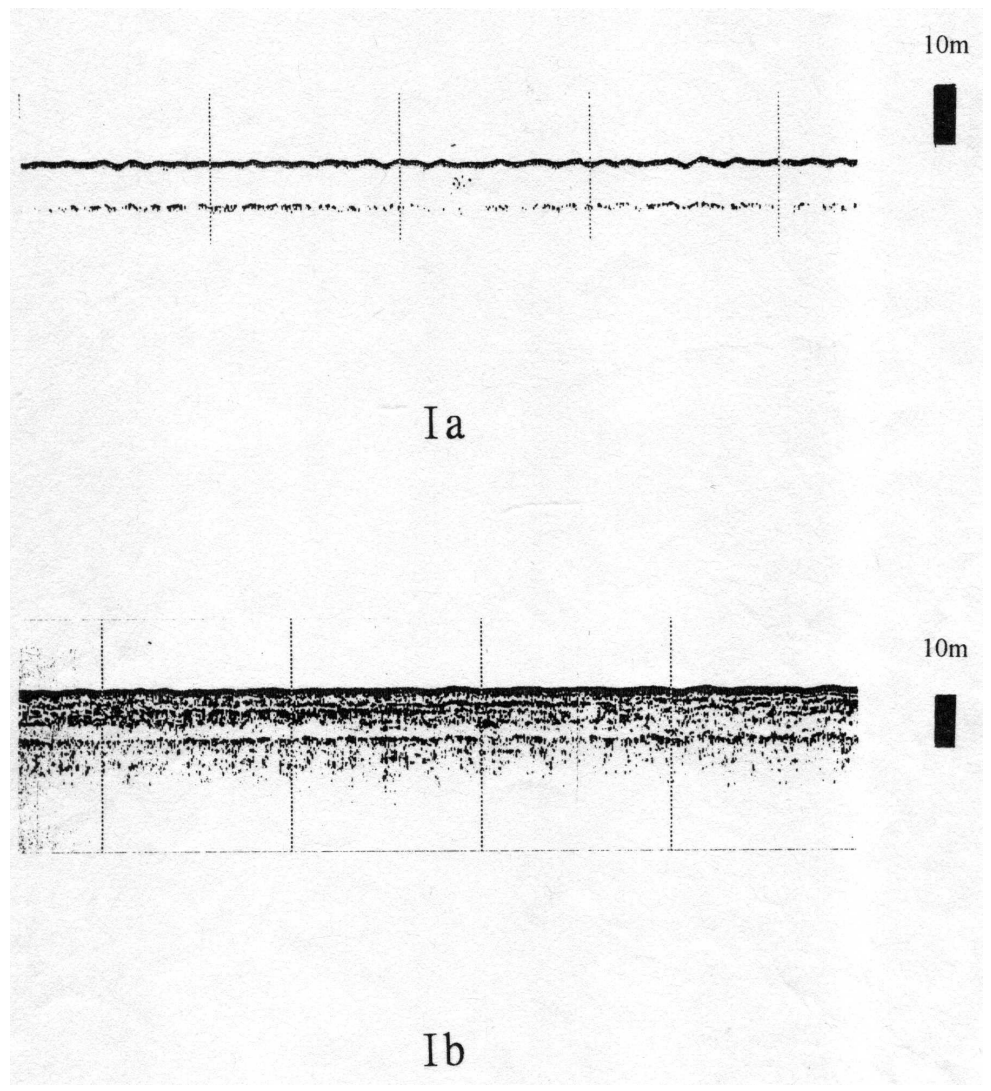

Fig. 5. Distinct echoes without sub-bottom reflectors (Ia); Distinct echoes with indistinct parallel, continuous sub-bottom reflectors (Ib). 


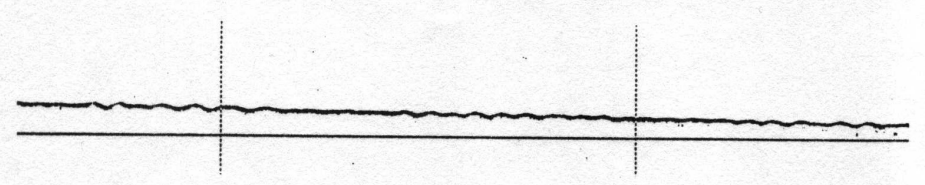

II a

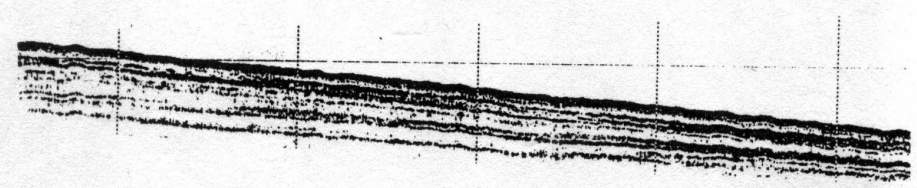

$10 \mathrm{~m}$

II $\mathrm{b}$

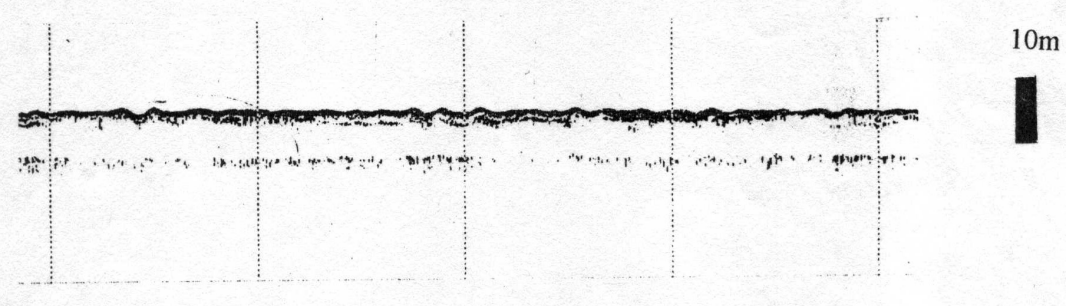

II $\mathrm{C}$

Fig. 6. Distinct echoes without sub-bottom reflectors (IIa); Distinct echoes with parallel continuous sub-bottom reflectors (IIb). Distinct echoes with vague discontinuous sub-bottom reflectors or simply semiprolonged (IIc). 


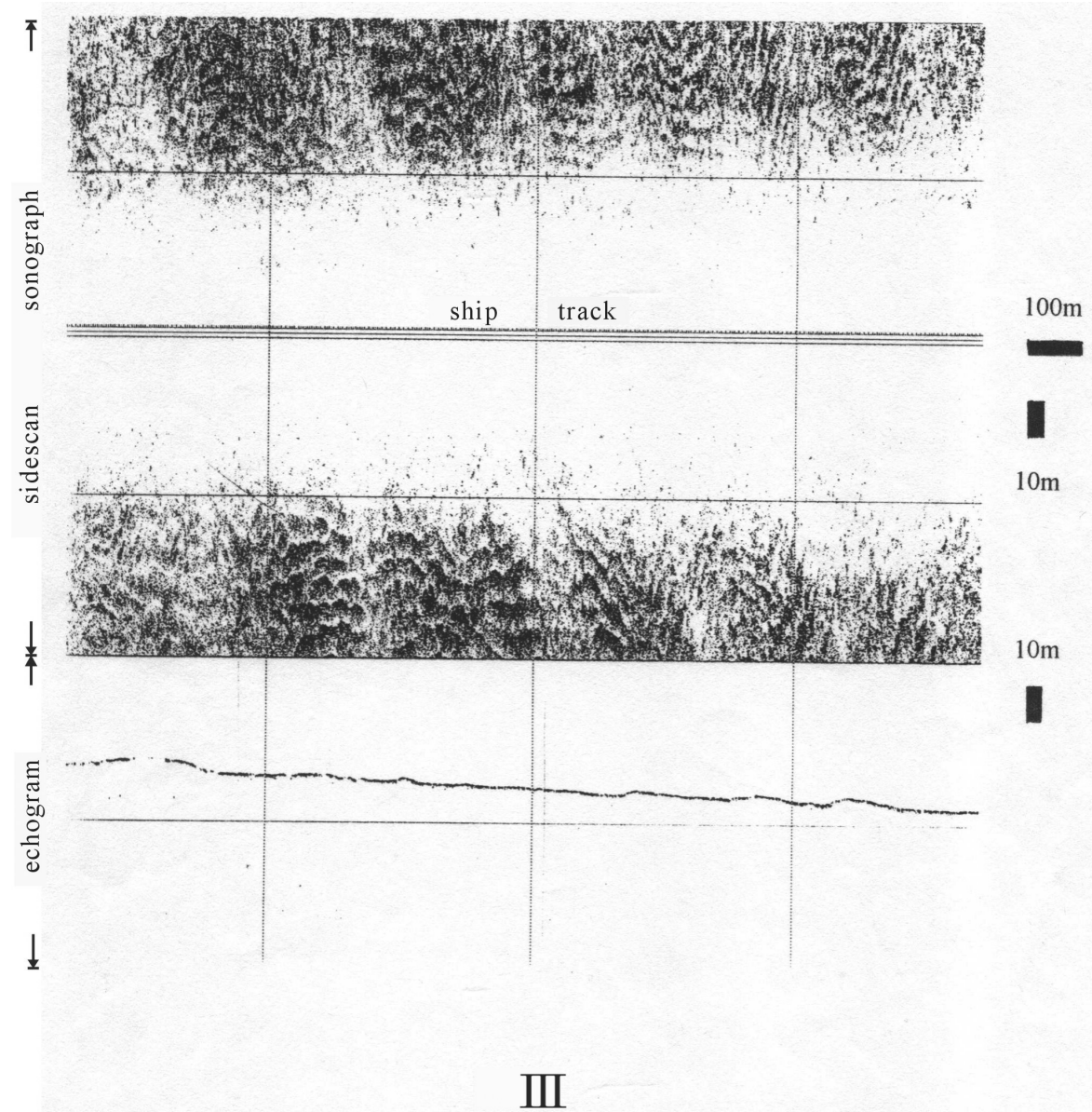

Fig. 7. Combined sidescan sonograph and subprofiler echogram (III). The range of the sediscan per trackline is $100 \mathrm{~m}$. The top two stripes are the sidescan sonograph showing very large 2-D dunes with medium 2-D dunes developed in the trough areas. The lowest stripe is echogram presenting distinct to semi-prolonged bottom echoes.

B. Indistinct Echoes:

Indistinct echoes have a prolonged or semi-prolonged bottom echo. Only one subclass is distinguished.

IV. Prolonged to semi-prolonged bottom echoes with hyperbolic interference (Fig. 8). The counterpart sidescan sonograph reveals a well-developed 2-D dune field. The wavelength of these dunes ranges from $3.6-8 \mathrm{~m}$ with $0.2-0.6 \mathrm{~m}$ in wave height. 


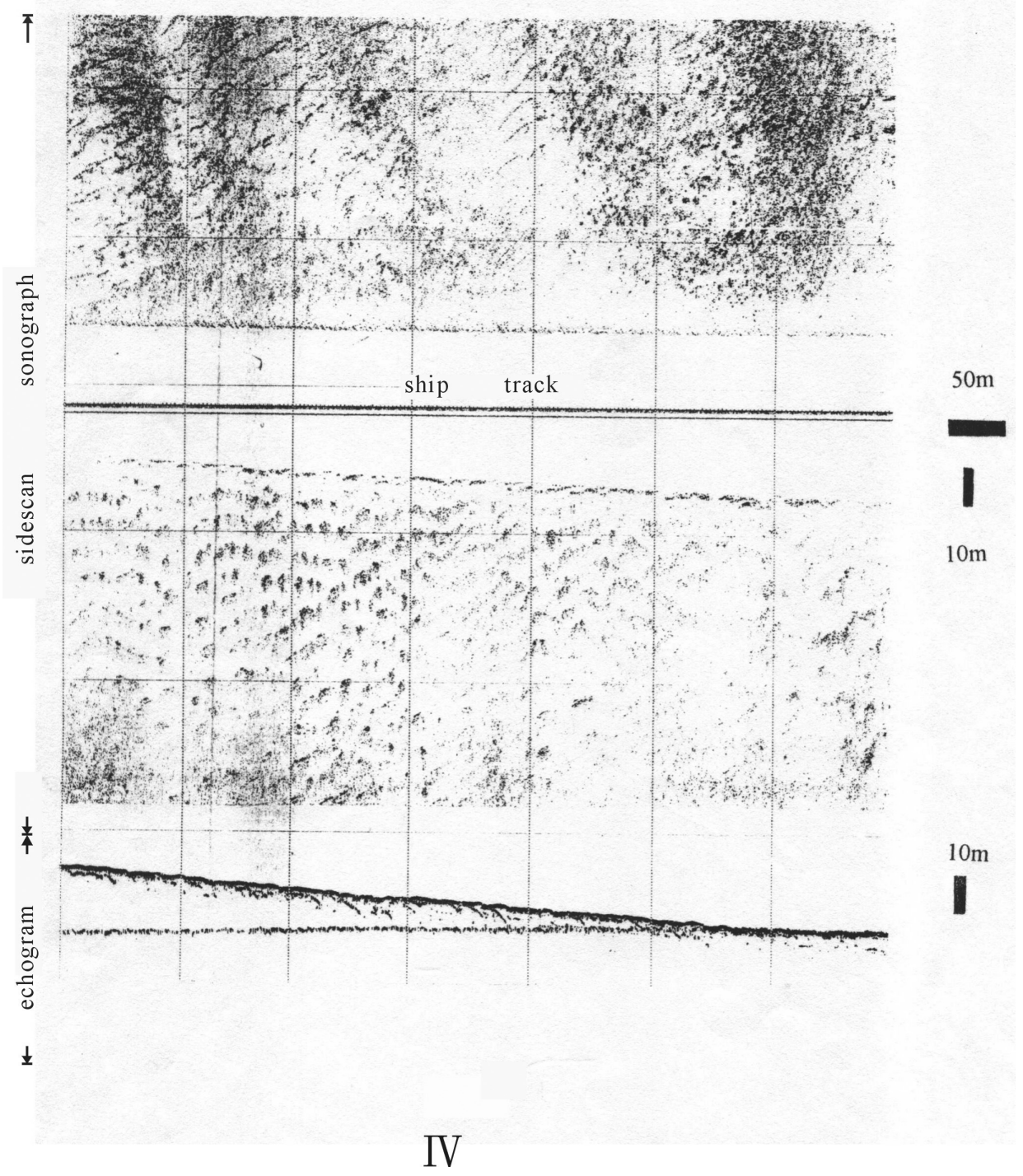

Fig. 8. Combined sidescan sonograph and subprofiler echogram (IV). Prolonged to semi-prolonged bottom echoes with hyperbolic interference discernible on the lower echogram. The counterpart side-scan sonograph reveals a well-developed 2-D dune field.

\subsection{Sediment Sample Analysis}

Based on nearly 600 kilometers of Chirp sonar echograms, the above seven distinct echo types are mapped (Fig. 9) according to guidelines of Damuth 1980. Totally 150 grab samples were then collected from the sea bottom of various echo-character areas. Grain size analyses 


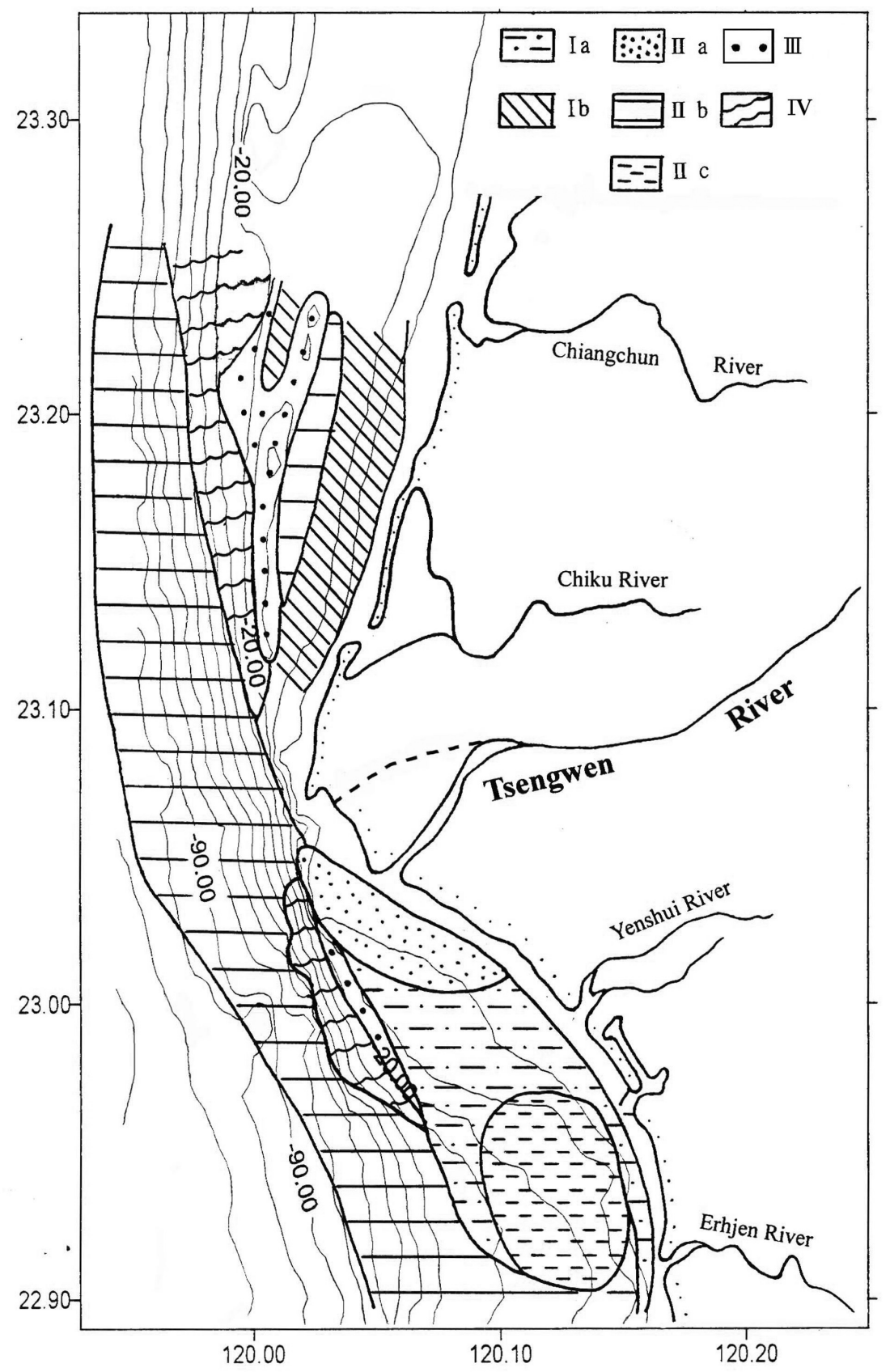

Fig. 9. Echo character map in front of the Tsengwen Delta. The description of echo types is in the text. 
of the samples were conducted using a combination of wet sieve and Galai CIS - 1 laser sizer techniques. A close relationship between mean grain size, various echo types and backscatter intensity has been well demonstrated in many previous studies (Addy et al. 1982; Alexander jr. et al. 1986; Schwab et al. 1996). In this study, the mean grain size of each sample are also measured and contoured (Fig. 10) to correlate with the established echo character map (Fig. 9).

A contour map of the mean grain size distribution (Fig. 10) was plotted with "Surfer" software. The boundaries of each size range were chosen and tested many times until the contoured pattern fit well with the echo character map. As indicated on the size contour map, most of the echo types are characterized by one specific mean grain size range. Among them, the finest fraction $(\mathrm{d}<74 \mu \mathrm{m})$ and the very fine sand size range $(74<\mathrm{d}<120 \mu \mathrm{m})$ fit well with the echo type IIc and IIb respectively. All echo types Ib, IIa and IIIa are characterized by the same size range, from coarse fine sand to medium sands $(260>d>178 \mu \mathrm{m})$. The sediment represented by echo type IIIb is composed of finer fine sands $(120<\mathrm{d}<178 \mu \mathrm{m})$. Finally, only echo type Ia occupies an area with a wide grain size range $(\mathrm{d}<178 \mu \mathrm{m})$.

\subsection{Interpretation of the Echo-Character Map}

The distribution of sediments and bedforms can reveal the processes of sedimentation, transportation and erosion ((Damuth 1980; McClennen 1989; Pratson and Laine 1989; Harris et al. 1993; Kuijpers et al. 1993; Byrnes and Hiland 1995; Morang et al. 1997). As such, regional echo characters, contoured grain size data and bedforms can be then integrated and mutually correlated to interpret an echo-character map allowing for the mapping of the sediment distribution in the northern and southern offshore regions of the Tsengwen Delta.

\subsubsection{Northern Offshore of the Tsengwen Delta}

Subaqueous delta plain:

The major part of the subaqueous delta plain, roughly from shoreface seaward to the 17meter-contour, is characterized by thick distinct bottom echoes with indistinct parallel continuous sub-bottom reflectors (Type Ib). The seafloor is covered by moderate to well sorted fine-grained sands with scattered shell debris. The mean grain sizes range from $0.147-0.217$ $\mathrm{mm}$ being slightly finer than those well to very well sorted fine-grained sands $(0.18-0.24 \mathrm{~mm}$. mean grain sizes) of the foreshore sediments. On the side-scan sonograph collected during different tidal cycles and monsoon seasons, different types and scales of ripples and dunes are identified indicating different hydrodynamics prevailed temporally.

Type IIb also appears in a narrow belt right by the landward side of the NNE-SSW trending sand ridge. The sediment is muddy silt but slightly sandier than those on the middle to lower delta slopes with mean grain sizes ranging from $0.065-0.145 \mathrm{~mm}$.

Ridge and upper delta slopes:

The NNE-SSW extending ridge, located at the edge of the subaqueous delta plain, is characterized by distinct to semi-prolonged echoes with a long wavelength wavy surface (Type III). Very large 2-D dunes with medium 2-D dunes developed in the trough were revealed on the sidescan sonograph (Fig. 7). The sediment samples are composed of well-sorted medium- 


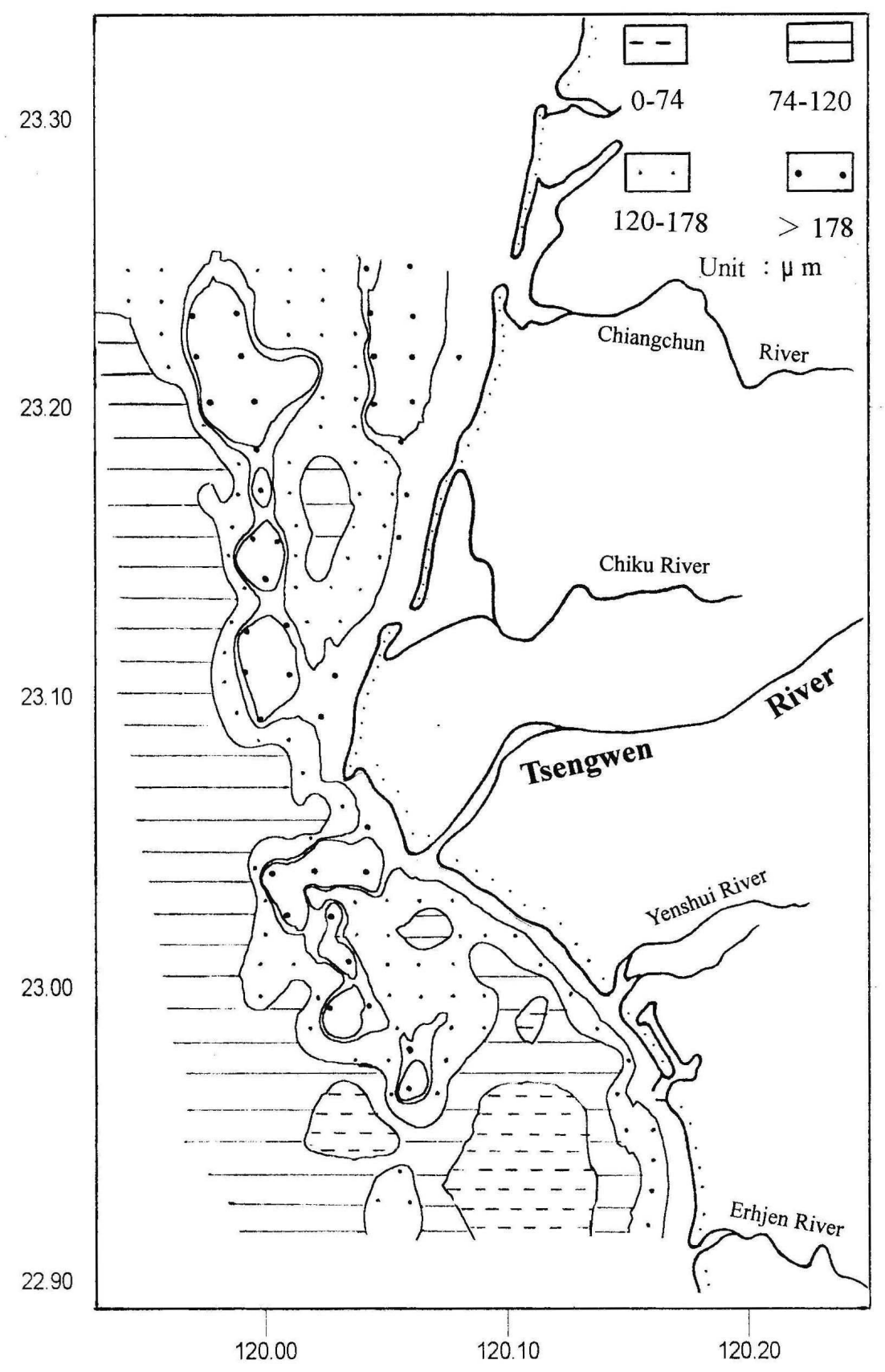

Fig. 10. The mean grain size distribution map correlates well with the echo character map. The mean grain size is in $\mu \mathrm{m}$ unit. 
grained sands (mean grain sizes $0.24-0.35 \mathrm{~mm}$ ) with subordinate fine-grained sands $(0.217$ $0.24 \mathrm{~mm}$ ). Away from the bordered ridge seaward to the upper delta slope, the echo type is turned into prolonged echo superimposed upon by interfered hyperbola (Type IV). The hyperbolic interference is caused by the undulation morphology effect of the medium 2-D dunes (wavelength, $3.6-8 \mathrm{~m}$; wave height, $0.2-0.6 \mathrm{~m}$ ) as shown on the counterpart side-scan sonograph (Fig. 8). The mean grain sizes also range from fine-to medium-grained sand (0.217 - $0.35 \mathrm{~mm}$.) but gradually fining downward toward the lower part of this echo type area. Delta slope and prodelta:

Distinct echoes with parallel continuous sub-bottom reflectors (Type IIb) were predominantly returned from the middle to lower part of the delta slope and prodelta. As the delta slope inclined seaward, the surface echo and paralleled continuous sub-bottom reflectors dipped and converged downwards. The sediment in this area is dominated by muddy silt of mean grain size ranging from $0.065-0.117 \mathrm{~mm}$; the muddiness of the sediment increasing toward the prodelta.

\subsubsection{Southern Offshore of the Tsengwen Delta}

Subaqueous delta plain:

Most of the area near the apex of the delta is shallower than $10 \mathrm{~m}$. As a result, this shallow region was rarely covered by seismic lines and only a few samples were taken. The sediment is mostly well-sorted, medium- to fine-grained sands with mean grain sizes ranged from 0.19 - $0.28 \mathrm{~mm}$. Off the Tsengwen River mouth, thin distinct bottom echoes without sub-bottom reflectors (Type IIa) were received from a semicircular area. The sediment is moderate to well-sorted, medium- to fine-grained sands $(0.147-0.35 \mathrm{~mm})$. Small-scale bedforms are common and varied in this area.

Southward from the above semi-circular area, the subaqueous delta plain is characterized by thick distinct bottom echoes without subbottom reflectors (type Ia). This area is composed of poorly to moderately sorted very fine- to fine-grained muddy sands $(0.117-0.147 \mathrm{~mm}$.). Further south, thin distinct echoes with vague discontinuous sub-bottom reflectors or simply semiprolonged (type IIc) were detected from a muddy oval-shape area (Fig. 9). The mean grain sizes are all less than $0.0625 \mathrm{~mm}$.

Delta slope:

There is no marginal ridge in the outer edge of the southern subaqueous delta plain, echo type III is still recognized from the slim edge. Similarly, downward from the edge echo type IV characterizes the upper delta slope while the rest of the delta slope and prodelta are dominated by echo type IIa. The sediment is similar to that of its northern counterpart under the same echo type.

\section{DISCUSSIONS}

The sediment distribution in front of the retreating Tsengwen River Delta is delineated based on the continuous profiler and sidescan combined sonar coverage and bottom sampling. Various sedimentary deposits are mainly controlled by different sedimentary processes pre- 
vailed at different morphologic areas. Therefore, the regional sediment transportation and deposition processes will be discussed and interpreted according to the sediment distribution and bedforms.

\subsection{Apex of Tsengwen Delta}

The subaqueous delta plain off the cusp of the delta is very shallow $(<15 \mathrm{~m})$ and narrow $(<3 \mathrm{~km})$. The sediments sampled here are well-sorted sands indicating energetic wave winnowing. Meanwhile, this part of shoreline was observed retreating 25 to $100 \mathrm{~m}$ within a one-year period (Shih 1996). Evidently, this protruded headland is constantly attacked and eroded by both seasonal monsoon wind waves and occasional storm waves. (Wen et al. 1995)

\subsection{Northern Offshore}

On the subaqueous delta plain, the orientation of the marginal sand ridge and the distribution patterns of sediments, as presented by echo type $\mathrm{Ib}$ and IIb, are mainly parallel to the shoreline (Fig. 9). As observed from the sidescan sonograph, wave crests of the symmetric and asymmetric 2-D bedforms are generally perpendicular to the shoreline indicating alongshore transportation of sediments in both monsoon seasons. Meanwhile, the sediment is also getting finer toward the west, from fine/medium sands to muddy silt. Accordingly, an offshore transportation of finer sediments should also be existent.

As to the morphology and sediment distribution in front of a retreating delta, there are various conditions characterizing different stages of delta abandonment as was recognized at different parts of the Mississippi Delta (Wright 1977; Elliott 1986). Among them, a series of barrier islands forms through the erosion of the delta front and pile-up of sandy sediments by wave actions during the initial stages of delta abandonment. When the retreating delta evolves further, the barrier islands are continuously reshaped in response to the local hydrodynamic processes (List et al. 1997; McBride, et al. 1997). Finally, a thin sand sheet develops at the expense of the barrier islands in the more advanced abandonment stage.

Inconsistent with the above description, there exists only a subaqueous sand ridge instead of barrier islands in front of the Tsengwen Delta. This sand ridge should have been formed as well by the wave actions indicated by well-sorted sandy sediments and wave-generated symmetrical bedforms (Type III). However, it seems that the sea level did not hold still long enough for the subaqueous sand ridge to grow high enough to form a barrier island.

This marginal sand ridge is separated from the shoreline to the east by a muddy belt (Type IIa). Which mean that at present there are no sediment sources contributing sands to the sand ridge. These sediments had been reported as relict sediments (Boggs et al. 1979; Liu et al. 1998). However, since they have been reworked by modern hydrodynamic processes these sandy deposits have to be palimpsest sediments.

Upon the upper delta slope (represented by Type IV), the sandy sediment mainly drifts northward and downward from the ridge as inferred from the directionality represented by asymmetric 2-D bedforms and the diminishing direction of the sand field. In the Taiwan Strait, current velocity is weaker during the northeasterly monsoon than during the southwesterly 
monsoon. However, currents flowing at 30 to $100 \mathrm{~m}$ in the region including the study area flow northward all year around (Shaw 1992; Jan et al. 1998; Liang et al. 2003). The sediment distribution and transportation observed and interpreted above is consistent with documented physical oceanographic data (Shaw 1992; Wen et al. 1995; Liang et al. 2003).

From the mid-delta slope downward to the prodelta is a sink of fine particles. The average gradient of the northern delta slope is $0.67^{\circ}$, which is gentler than its southern counterpart. However, the seaward inclination of distinct echoes and its subbottom continuously parallel reflectors reveal the progradation nature of the delta as with other deltas (Elliott 1986). Although long piston cores are not available in this study to correlate subbottom profiles, similar echo types and their progradational interpretations are commonly reported and can be easily inferred from other deltaic settings (Alexander Jr. et al. 1986; Nittrouer et al. 1986; Chronis et al. 1991; Vital et al. 1998).

\subsection{Southern Offshore}

Southward from the river mouth of the Tsengwen River, the shoreline is curved gently in plan as a lunette shaped bay (Fig. 2). Which is different from the linear shoreline in the northern counterpart. Without having a marginal ridge, the incoming waves refract in this shallow bay with crests roughly parallel to the shoreline while breaking down. Under such condition an alongshore current is absent with little alongshore drift occurring (Silvester and Hsu 1993; Silvester et al. 1995; Thurman and Burton 2001). Meanwhile, this southern part of the shoreline has been reported as being very stable in past years (Shih et al. 1995; Hong et al. 1995) and likewise during this study period.

Upon the subaqueous delta plain, the distribution pattern of the sediments is quite different from the northern one (Fig. 9). Near the apex of the Tsengwen Delta and the river mouth, where effective wave actions prevailed, the sediment is composed of well-sorted fine-to medium-grained sands. Within these sediments, flaser bedding was observed in two box cores indicating tidal effects existed besides the constant wave action. Since the well-sorted sandy sediments (type IIa) cover a semicircular-like area right in front of the river mouth, it delineates the full distribution extent of the bed-load sediments output from the Tsengwen River.

On the southeastern part of the subaqueous delta plain, the mud content is increased as grain size gets finer (echo type Ia). Most strikingly, an oval-shape like mud belt is found in the central southern region (characterized by echo type IIc). The reasons for an increase and settling of mud content are more likely to be: (1) Continuous input of muddy sediment from the Erhjenchi River, since the sediment discharged from the river is mainly composed of clayey materials (Shih et al. 1995). (2) Free settling of suspension governed by gyratory circulation. The formation of the gyratory circulation is due to the obstruction of the northwardly currents by the promontory of the Tsengwen Delta. As a result, eddies are developed on the subaqueous delta plain (Hong et al. 1995). This gyratory circulation pattern was well demonstrated by a drifter experiment (Tseng et al. 1997). Tseng et al. (1997) also pointed out that less seasonal current variations and more effective tidal processes prevail in this region. Therefore, the developed eddies and tidal effects have controlled and promoted the deposition of muddy sediments on the southern subaqueous delta plain. 
Although not piled up to form a ridge as the northern counterpart, well sorted coarser sediments spread upon the edge of the subaqueous delta plain (Type III) as a linear sandy shoal (Fig. 9). The sheet like sandy shoal accompanied by stable shorelines (Shih et al. 1995; Hong et al. 1995) signifies a more advanced stage of delta abandoment than the northern counterpart. Meanwhile, due to the sediments having the same characteristics as the northern sandy ridge, they are also palimpsest and drift northward and downward under the same current and tidal actions.

Similarly, the same foreset progradation features are also observed along the lower delta slope and prodelta. Howerer, the finer sediment input from the nearby river and a suitable gyratory hydrodynamic circulation favor more muddy sediment distribution and a steeper delta slope (average $1.36^{\circ}$ ).

\section{CONCLUSIONS}

Due to the construction of a river dam, the shoreline of the Tsengwenchi Delta is undergoing erosion and retreat just as many other deltas have confronted (Coleman et al. 1981; Guillen and Palanques 1993). Extensive combined profiler and sidescan sonar investigation data, bathemetry and surface sediments analyses have well revealed the subaqueous morphology, bedforms and sediment distribution in front of the retreating delta. The interpretaion from these integrated findings allows us to better understand processes that controll sediment influx, transportation and distribution. Accordingly, the shoreline response and the future evolution of this destructive delta are then delineated and predicted (Fig. 11).

Differential stages of abandonment occur in between the northern and southern part of the Tsengwen Delta. The starved lagoons behind the barrier islands prevent the river-born sediment from flowing out to nourish the northern part of the shoreline and offshore regions. Therefore, there is no outward sediment distribution in front of the inlets. Instead, the parallelity between the distribution trends of the sediments and shoreline along with the crests of 2D subaqueous dunes perpendicular to the shoreline indicate that the prevailing forces influencing the northern subaqueous delta plain were predominant alongshore transportation and effective wave action. The lack of sediment input, and the retreating shoreline, marginal sand ridge and the ever-changing topography in the ridge and delta slope indicate that the northern part of the Tsengwen Delta is abandoned. In addition, this receding and unstable status will continue.

Although sediment quantity is significantly reduced, it is still fluxing out from the Tsengwen River to replenish the nearby shoreline and offshore. Besides wave action, tidal processes and gyratory circulations are the main factors controlling sedimentation of fine particles and regional sediment distributions on the southern subaqueous delta plain.

The stable shoreling and subaqeous settings along with a marginal linear sandy shoal indicate that a more advanced stage of delta abandonment exists in the southern counterpart. The sediment input from the river is not plentyful enough to prograde again. However, it does stop the shoreline from further receding. Without any further natural or human tampering, the southern Tsengwen Delta ought be able to keep and proceed at equilbrium status. 


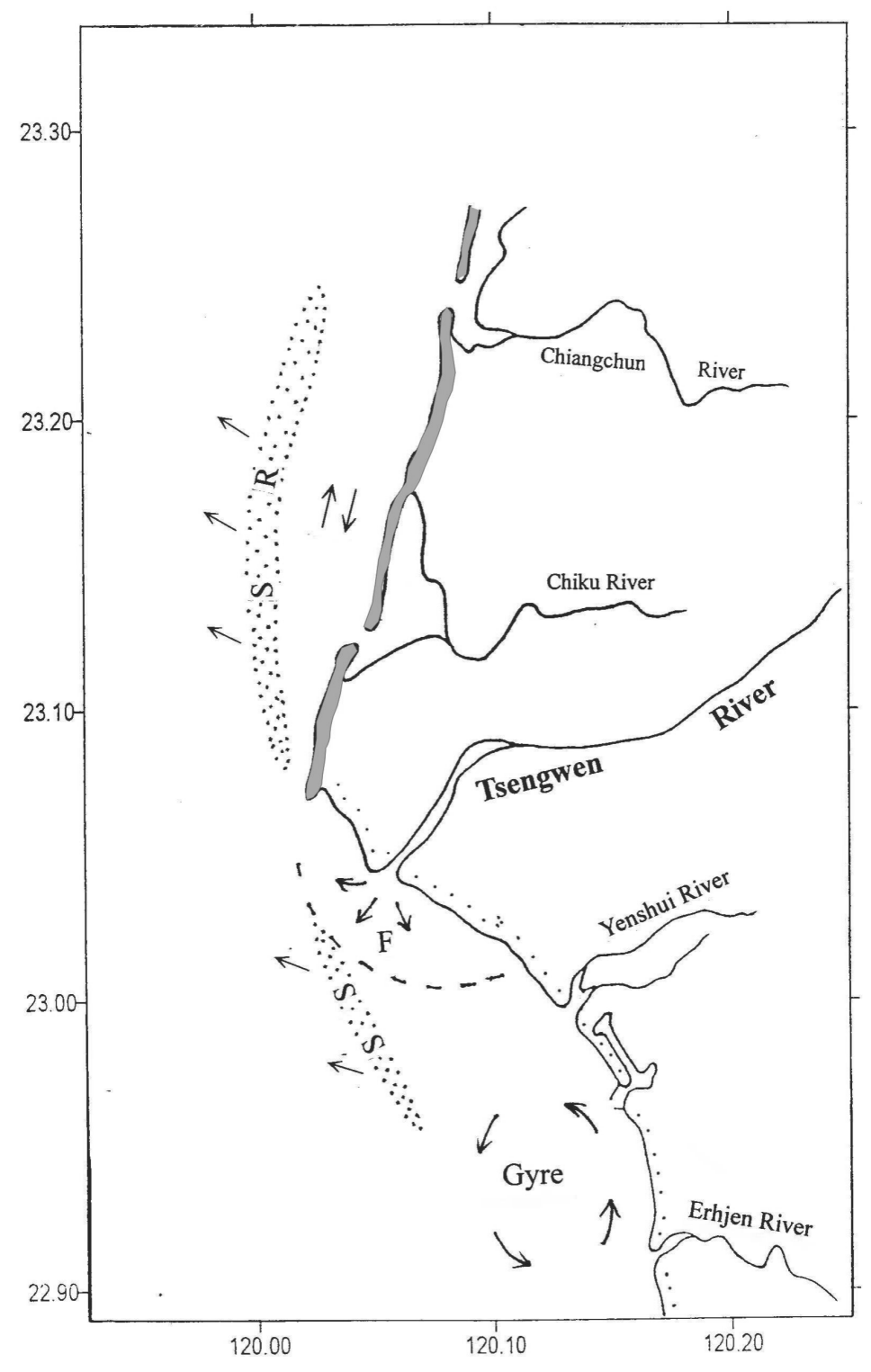

Fig. 11. The map shows the location of the subaqueous sand ridge (SR) and shoal (SS) where covered by well-sorted palimpsestic sandy sediments. Recent fluvial sediment is distributed in a semi-circular area $(F)$, delineated by the dashed line, right in front of the river mouth. The stable dynamic equilibrium and the erosional receding parts of the shorelines are marked as dotted and shaded areas respectively. Solid arrows indicate sediment transportation patterns. 
Acknowledgements The authors are indebted to the crew of R/V Ocean Researcher II for their help in collection data. Many beneficial comments provided by J. D. Milliman greatly improve the clarity of the paper. The authors also thank T. E. Tseng and W. C. Thou for helping them type and draft this manuscript. Financial support for the research is provided by the National Science Council of Taiwan under the Grant NSC87-2621-P-019-001.

\section{REFERENCES}

Addy, S. K., E. W. Behrens, T. R. Haines, D. J. Shirley, and J. L. Worzel, 1982: High-frequency subbottom reflection types and lithologic and physical properties of sediment. Mar. Geotech., 5, 27-49.

Alexander, Jr. C. R., C. A. Nittrouer, and D. J. DeMaster, 1986: High-resolution seismic stratigraphy and its sedimentological interpretation on the Amazon continental shelf. Continen. Shelf Res., 6, 337-357.

Ashley, G. M., 1990: Classification of large-scale subaqueous bedforms: a new look at an old problem [symposium]. J. Sedim. Petrol., 60, 160-172.

Boggs, S., W. C. Wang, F. S. Lewis, and J. C. Chen, 1979: Sediment properties and water characteristics of the Taiwan shelf and slope. Acta Oceanogr. Taiwan, 10, 10-49.

Byrnes, M. R., and M. W. Hiland, 1995: Large-scale sediment transport patterns on the continental shelf and influence on shoreline response: St. Andrew Sound, Georgia to Nassau Sound, Florida, USA. Marine Geol., 126, 19-43.

Chang, J. C., 2000: Geomorphological change on the Tsengwen coastal plain in southwestern Taiwan. Geomorphology, Human Activity and Global En. Change, 235-247.

Chen, H. L., and J. C. Chang, 2001: Effect of Tsengwen Reservoir on channel morphology. Proc. the $5^{\text {th }}$ Taiwan Geogr. Conf., 20-37.

Chronis, G. D., J. W. Piper, and C. Anagnostou, 1991: Late Quaternary evolution of the Gulf of Patras, Greece: tectonism, deltaic sedimentation and sea-level change.Marine Geol., 97, 191-209.

Coleman, J. M., H. H. Roberts, S. P. Murray, and M. Salama, 1981: Morphology and dynamic sedimentology of the eastern Nile Delta shelf. Marine Geol., 42, 301-326.

Damuth, J. E., 1980: Use of high-frequency (3.5 - $12 \mathrm{kHz}$ ) echograms in the study of near bottom sedimentation processes in the deep-sea: a review. Marine Geol., 38, 51-75.

Elliott, T., 1986: Deltas. In: Reading, H. G., (Ed.), Sedimentary Environments and Facies, MA. Blackwell Sci. Pub., 113-154.

Galloway, W. E., 1975: Process framework for describing the morphologic and stratigraphic evolution of deltaic depositional system. In: Broussard M. L., (Ed.), Deltas, Models for Exploration. Houston Geol. Soc., Houston, 87-98.

Guillen, J., and A. Palanques, 1993: Longshore bar and trough systems in a microtidal, stormwave dominated coast: the Ebro Delta. Marine Geol., 155, 239-252. 
Harris, P. T., E. K. Baker, A. R. Cole, and S. A. Short, 1993: A preliminary study of sedimentation in the tidally dominated Fly River Delta, Gulf of Papua. Continen. Shelf Res., 13, 441-472.

Hong, E., and I. S. Chen, 2000: Echo characters and sedimentary processes along a rifting continental margin, northeast of Taiwan. Continen. Shelf Res., 20, 599-617.

Hong, E. H., S. Yu, and I. S. Chen, 1992: A preliminary study of the echo characters and sedimentary processes along the continental margin, northeast of Taiwan. TAO, 3, 435447.

Hong, E., C. H. Tsai, C. H. Ou, H. S. Tseng, and J. Y. chi, 1995: A study on the seasonal sediments transportation off the Tsengwenchi Delta. Proc. of $17^{\text {th }}$ Ocean Engin. Conf., 1327-1342.

Jan, S., C. S. Chern, and J. Wang, 1998: A numerical study of currents in Taiwan Strait during winter. $T A O, 9,615-632$.

Knebel, H. J., 1993: Sedimentary environments within a glaciated estuarine-inner shelf system: Boston Harbor and Massachusetts Bay. Marine Geol., 110, 7-30.

Kuijpers, A., F. Werner, and J. Rumohr, 1993: Sandwaves and other large scale bedforms as indicators of non-tidal surge currents in the Skagerrk off Northern Denmark. Marine Geol., 111, 209-221.

LeBlanc, L. R., S. Panda, and S. G. Schock, 1992: Sonar attenuation modeling for classification of marine sediments. Acous. Soc. Am., 91, 116-126.

List, J. H., B. E. Jaffe, A. H. Sallenger Jr., and M. E. Hansen, 1997: Bathymetric comparisons adjacent to the Louisiana Barrier Islands: processes of large-scale change.J. Coastal Res., 13, 670-678.

Liu, J. T., P.B. Yuan, and J. J. Hung, 1998: The coastal transition at the mouth of a small mountainous river in Taiwan. Sedimentol., 45, 803-816.

McBride, R. A., and M. R. Byrnes, 1997: Regional variations in shore response along barrier island systems of the Mississippi River delta plain: historical change and future prediction. J. Coastal Res., 13, 628-655.

McClennen, C. E., 1989: Microtopography and surficial sediment patterns in the central Gulf of Marine: a $3.5 \mathrm{kHz}$ survey and interpretation. Marine Geol., 89, 69-85.

Morang, A., R. Larson, and L. Gorman, 1997: Monitoring the coastal environment: Part III: geophysical and research methods. J. Coastal Res., 13, 1064-1085.

Moustier de, C., and H. Matsumoto, 1993: Seafloor acoustic remote sensing with multibeam echo-sounders and bathymetric sidescan sonar system. Marine Geophys. Res., 15, 2742.

Nittrouer, C. A., S. A. Kuehl, D. J. DeMaster, and R. O. Kowsmann, 1986: The deltaic nature of Amazon shelf sedimentation. Geol. Soc. Am. Bull., 97, 444-458.

Pratson, L. F. and E. P. Laine, 1989: The relative importance of gravity-induced versus current-controlled sedimentation during the Quaternary along the Mideast U.S. outer continental margin revealed by $3.5 \mathrm{kHz}$ echo character. Marine Geol., 89, 87-126.

Schwab, W. C., R. W. Rodriguez, W. W. Danforth, and M. H. Gowen, 1996: Sediment distribution on a storm-dominated insular shelf, Luquillo, Pureto Rico, U. S. A.J. Coastal Res., 12, 147-159. 
Shaw, P. T., 1992: Shelf circulation off the southeast coast of China. Reviews in Aquatic Sciences, 6, 1-28.

Shih, S. M., 1996: Beach morphology and coastal remote sensing on the Tsengwenchi Delta. Proc. $6^{\text {th }}$ Joint Symp. Taiwan Quatern., 186-189.

Shih, T. T., J. C. Chang, H. M. Lin, C. L. Chang, M. C. Liu, and C. T. Chen, 1995: A geomorphological study on the southwestern estuaries in Taiwan. Geogr. Res., Natl. Taiwan Normal Univ., 23, 109-150.

Silvester, R., and J. R. C. Hsu, 1993: Coastal Stabilization, innovative concepts. Prentice Hall, Inc., New Jersey, 578 pp.

Silvester, E. R., A. L. Brill, W. J. Cleary, C. H. Hobbs III, and R. A. Gammisch, 1995: Geology of the Wrightsville Beach, north Carolina shoreface: implication for the concept of shoreface profile of equilibrium. Marine Geol., 126, 271-287.

Tseng, R. S., K. R. Hsu, and K. H. Liao, 1997: Observations of surface currents and horizontal diffusion in coastal waters of Tainan and Kaohsiun. Proc. NSC Rept. Joint Project on Land-Ocean Interaction in the Coastal Zone, 6-27.

Tseng, S. S., T. C. Huang, W. P. Liu, and E. Hong, 1996: Precision depth surveying of the subaqueous topography off the Chayie-Tainan region. Proc. $6^{\text {th }}$ Joint Symp. Taiwan Quatern., 170-173.

Vital H., K. Stattegger, J. Posewang, and F. Theilen, 1998: Lowermost Amazon River: morphology and shallow seismic characteristics. Marine Geol., 152, 277-294.

Wen, J. T., J. S. Luo, M. S. Sheu, and W. S. Chiang, 1995: Oceanic investigation of topography, wave and current in the vicinity of Taiwan City. Proc. $17^{\text {th }}$ Ocean Engin. Conf., Tainan, Taiwan, 1125-1138.

Wright, L. D., 1977: Sediment transport and deposition at river mouths: a synthesis. Geol. Soc. Am. Bull., 88, 857-868.

Yeh, C. L., C. L. Luo, C. R. Chen, and S. P. Chang, 1994: Assessment of economic aspects of submarine aggregate mining in the Chiayie offshore area. Tech. Rep. to Industrial Tech. Res. Energy Res. Lab., Taiwan 105 p. 